Dirkzwager, A.J.E., Bramsen, I., Ploeg, H.M. van der

Social support, coping, life events, and posttraumatic stress symptoms among former peacekeepers: a prospective study.

Personality and Individual Differences: 34, 2003, p. 1545-1559

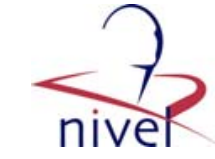

\begin{tabular}{l|l} 
Postprint Version & 1.0 \\
\hline Journal website & http://www.sciencedirect.com/science/journal/01918869 \\
\hline Pubmed link & \\
\hline DOI & $10.1016 /$ S0191-8869(02)00198-8
\end{tabular}

\title{
Social support, coping, life events, and posttraumatic stress symptoms among former peacekeepers: a prospective study
}

\author{
ANJA J.E. DiRKZWAGER*, I. BRAMSEn, HenK M. VAN DER Ploeg \\ Department of Medical Psychology, Vrije Universiteit Amsterdam, Van der Boechorststraat 7, 1081 BT \\ Amsterdam, The Netherlands \\ * Corresponding author. Tel.: +31-71-5212107; fax: +31-20-4448230. \\ E-mail address: a.dirkzwager@nivel.nl (A.J.E. Dirkzwager).
}

\begin{abstract}
This study examined both cross-sectionally and longitudinally the relationship between social support, coping strategies, additional stressful life events, and symptoms of posttraumatic stress disorder (PTSD) among Dutch former peacekeeping soldiers. Two groups of peacekeepers were investigated: 311 peacekeepers who participated in the peacekeeping operation in Lebanon between 1979 and 1985, and 499 peacekeepers who were deployed after 1990. These peacekeepers completed a questionnaire in 1996 and again in 1998. The results show that more negative social contacts and fewer positive social contacts were associated with more PTSD symptom severity. More use of the coping strategies 'wishful thinking' and 'accepting responsibility' was related to more PTSD symptoms. Conversely, more planful problem solving and seeking social support was related to less PTSD symptom severity. In addition, a bilateral relationship was found between additional stressful life events and PTSD symptom severity. The results indicate that social support and coping strategies may be valuable aspects of prevention and intervention programs.
\end{abstract}

For years now, it has been known that exposure to combat-related stressful events can result in longterm psychological adjustment problems, such as posttraumatic stress disorder (PTSD) (Archibald \& Tuddenham, 1965; Bramsen \& Van der Ploeg, 1999; Friedman, Schnurr, \& McDonagh- Coyle, 1994; Kulka et al., 1990). PTSD is characterised by persistent intrusive memories about the traumatic event, by persistent avoidance of stimuli associated with the trauma, and by persistent symptoms of increased arousal (American Psychiatric Association, 1994). In recent years, the number of peacekeeping operations has increased creating a new group of military personnel. Peacekeeping operations are frequently associated with a lower stressor intensity than traditional combat situations (e.g. World War II and the Vietnam war). Nevertheless, peacekeeping personnel are subjected to potentially traumatic war-zone situations as well (Litz, 1996). During deployment peacekeeping personnel may be exposed to life-threatening situations, such as gunfire, being taken hostage, and hostile reactions of the conflicting parties. Meanwhile the peacekeepers are generally outmanned and outgunned, and the principle of non-use of force except for self-defence is central to the concept of peacekeeping. In addition, peacekeepers are increasingly involved in providing humanitarian aid and may witness human distress such as starving, sick or wounded persons. Studies investigating peacekeeping personnel have shown that, although many peacekeepers adjust well following deployment, a significant group may develop symptoms of posttraumatic stress disorder (Litz, Orsillo, Friedman, 
Dirkzwager, A.J.E., Bramsen, I., Ploeg, H.M. van der

Social support, coping, life events, and posttraumatic stress symptoms among former

peacekeepers: a prospective study.

Personality and Individual Differences: 34, 2003, p. 1545-1559

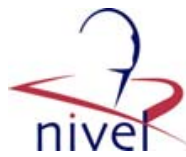

Ehlich, \& Batres, 1997; MacDonald, Chamberlain, Long, \& Mirfin, 1996; Mehlum \& Weisaeth, 2002; Weisaeth, Aarhaug, Mehlum, \& Larsen, 1993). The question remains why some peacekeepers develop PTSD symptoms while others do not. In addition to characteristics of the stressor, an individual's response to stress is considered to be influenced by the personal and environmental resources available to that person to deal with the stressor.

Studies on factors associated with PTSD symptoms among peacekeeping personnel have mainly focused on war-zone related factors, for example the degree of exposure to combat, positive and negative aspects of the peacekeeping operation, and personal factors (e.g. age, gender, race, and level of education) (Litz, King, King, Orsillo, \& Friedman, 1997; Litz, Orsillo et al., 1997). Few data are available on the relationship between social support/coping strategies and PTSD symptoms among peacekeeping personnel, and longitudinal studies investigating risk factors for PTSD symptoms among peacekeepers are scarce. Therefore, the present longitudinal study focuses on the role of social support (as an environmental resource), coping strategies (as a personal resource), and additional stressful life events as predictors for PTSD among Dutch former peacekeepers.

Social support is considered to be an important factor influencing reactions to stress. In general, two models of social support have been suggested: the main effect model and the buffering model (Cohen \& Wills, 1985). The main effect model suggests that social support has a beneficial effect irrespective of whether a person is under stress. The buffering model proposes that social support is beneficial only or primarily for persons under stress. Although there is no consensus about the relationship between social support and PTSD, having sufficient and satisfactory social support is generally associated with less psychological distress, such as PTSD (Cohen \& Wills, 1985; Flannery, 1990; Green, Grace, Lindy, Gleser, \& Leonard, 1990; King, King, Fairbank, Keane, \& Adams, 1998; Sarason \& Sarason, 1985). In the present study, supportive social interactions are expected to be associated with fewer PTSD symptoms.

Coping is defined as the cognitive and behavioural efforts to manage specific external and/or internal demands that are appraised as taxing or exceeding the resources of a person (Lazarus, 1993). In general, coping has two major functions: dealing with the problem that is causing the distress (problem-focused coping) and regulating emotions (emotion-focused coping) (Folkman, Lazarus, Gruen, \& Delongis, 1986). Most studies on coping among combat veterans indicate that using more emotion-focused coping is associated with more PTSD symptoms, whereas the use of problemfocused coping is associated with fewer PTSD symptoms (Fairbank, Hansen, \& Fitterling, 1991; Sharkansky, King, King, \& Wolfe, 2000; Solomon, Mikulincer, \& Avitzur, 1988; Solomon, Mikulincer, \& Flum, 1988; Sutker, Davis, Uddo, \& Ditta, 1995; Zeidner \& Ben-Zur, 1994). However, most of these studies are limited by a cross-sectional design. The longitudinal study of Benotsch, Brailey, Vasterling, Uddo, Constans, and Sutker (2000) among Gulf War veterans demonstrated that a higher level of avoidance coping at time 1 predicted more PTSD symptoms at time 2, even after controlling for emotional distress at time 1. In the present study it was hypothesised that the use of more problem-focused coping strategies (e.g. planful problem solving) would be associated with fewer PTSD symptoms, whereas the use of more emotionfocused coping strategies (e.g. wishful thinking, avoidance, and accepting responsibility) would be associated with more PTSD symptoms.

Several studies investigating risk factors for PTSD among combat veterans, found a significant relationship between stressful life events following the combat experience and current PTSD (Fontana \& Rosenheck, 1994; King, King, Foy, Keane, \& Fairbank, 1999). A longitudinal study among Gulf War Army personnel demonstrated a positive relationship between PTSD at time 2 and the number of negative life events in the preceding period (Sharkansky et al., 2000). This latter finding concurs with results from the longitudinal study of Solomon and colleagues among Israeli soldiers active in the Lebanon War (Solomon, Mikulincer, \& Flum, 1988). They demonstrated that 2 years postwar PTSD was significantly associated with the number of negative life events in the preceding year. In addition, 1 year postwar PTSD was positively and significantly correlated with the number of negative life events in the following year. In accordance with the study of Solomon and colleagues, it was hypothesised in the present study that more PTSD symptoms at time 1 would be significantly associated with a higher number of stressful life events in the preceding year and with a higher number of stressful life events in the following 2 years. It was also expected that more life events in the 
Dirkzwager, A.J.E., Bramsen, I., Ploeg, H.M. van der

Social support, coping, life events, and posttraumatic stress symptoms among former

peacekeepers: a prospective study.

Personality and Individual Differences: 34, 2003, p. 1545-1559

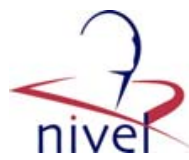

interval between the surveys (i.e. time 1 and time 2) would be significantly correlated with more symptoms of PTSD at time 2.

Thus, the aim of the present study was to examine the relationship between social support, coping strategies, additional stressful life events, and posttraumatic stress symptoms among former peacekeepers. The study design allowed us to: (a) make a cross-sectional examination of the relationship between social support, coping strategies, stressful life events and PTSD symptom severity at time 1; and (b) make a longitudinal examination of the relationship between social support, coping strategies, stressful life events and PTSD symptoms at time 2, after controlling for PTSD symptom severity at time 1 .

\section{METHOD}

\subsection{Subjects}

This study focuses on two groups: peacekeepers who participated in the international peacekeeping operation in Lebanon in the period 1979-1985, and peacekeepers who participated in international peacekeeping operations in the period 1990-1995. In 1996, 1476 of 2884 Dutch former peacekeepers (51\%) participated in a study that investigated veterans involved in international peacekeeping operations since 1975. Of these 1476 veterans, 422 participated in the peacekeeping operation in Lebanon and 946 participated in peacekeeping operations since 1990. In 1998, a follow-up study was carried out, in which 889 of the 1476 peacekeepers (60\%) returned a completed questionnaire. Of these 889 peacekeepers, 311 participated in the peacekeeping operation in Lebanon (1979-1985), and 499 participated in peacekeeping operations since 1990. Because differences in the time elapsed since deployment may be related to the occurrence of adjustment problems, the Lebanon veterans were examined separately because this operation took place several years prior to 1990. For both groups, chi-square tests and $t$-tests were used to explore whether those who participated in both the 1996 and the 1998 studies differed from those who participated in 1996 only, with respect to demographic and military characteristics, factors related to combat exposure, and health problems. The Bonferroni correction was used to decrease the risk for type 1 errors (alpha=0.007). Compared with the peacekeepers of operations since 1990 who participated in the 1996 study only, the 499 peacekeepers who participated both in 1996 and in 1998 were on average older $(t-=6.01 ; \mathrm{df}=635.31, P<0.001)$, and were more often of a non-commissioned officer or higher military rank $\left(x_{2}=13.07 ; \mathrm{df}=1 ; P<0.001\right)$. No significant differences were found between the peacekeepers of operations since 1990 who participated in both 1996 and in 1998 and the peacekeepers who participated only in 1996, with respect to the other variables: gender, level of education, marital status, PTSD symptom severity, sleeping problems, somatic complaints and the mean number of reported potentially traumatic situations during deployment. In addition, no significant differences were found between the peacekeepers of Lebanon who participated at both times and the peacekeepers of Lebanon who participated in 1996 only.

Table 1 presents the mean scores on the research variables for both groups of peacekeepers. Veterans from Lebanon reported significantly more potentially traumatic situations during deployment, more PTSD symptom severity, more negative social interactions, and more stressful life events in the year prior to 1996 than did the veterans of operations since 1990. Compared with the Lebanon veterans, the veterans of operations since 1990 reported significantly more positive social interactions and more often used the coping strategy 'positive reappraisal'.

\section{[ TABLE 1 ]}

\subsection{Procedure}

In 1996 (time 1) and in 1998 (time 2) the peacekeepers received a questionnaire and a letter explaining the purpose of the study. The completed questionnaire could be returned using a prepaid envelope, thereby giving informed consent. 
Dirkzwager, A.J.E., Bramsen, I., Ploeg, H.M. van der

Social support, coping, life events, and posttraumatic stress symptoms among former

peacekeepers: a prospective study.

Personality and Individual Differences: 34, 2003, p. 1545-1559

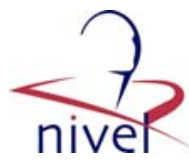

\subsection{Measures}

To measure current PTSD symptoms, the Self-Rating Inventory for PTSD (SRIP) was used (Hovens, Bramsen, \& Van der Ploeg, 2000; Hovens, Van der Ploeg, Bramsen, Klaarenbeek, \& Schreuder, 1994). The SRIP consists of three subscales corresponding to the three symptom clusters of the DSMIV: intrusion (6 items), avoidance (9 items), and hyperarousal (7 items). Some DSM-IV items are not formulated in a completely unambiguous way. In the SRIP all items are. Thus, in the SRIP, items such as 'difficulty falling or staying asleep' were expressed as two specific items: 'difficulty falling asleep' and 'difficulty staying asleep'. In this way 22 items were used to represent the original 17 DSM-IV items. A four-point Likert scale was used to measure the severity of each symptom (1=not at all; $4=\mathrm{a}$ great deal). The SRIP has proven to be reliable and valid (Hovens et al., 1994). Test-retest reliability correlation coefficient was 0.92 , and the internal consistency had an alpha coefficient of 0.92 . The scale correlated significantly with the Clinician Administered PTSD Scale (CAPS), the Mississippi Scale for Combat-related PTSD, the MMPIPTS D subscale and the Impact of Event Scale. Sensitivity and specificity of the SRIP in relation to the CAPS were found to be very good (sensitivity: 85\%; specificity: 70\%; Hovens et al., 1994). In the present study, the total score of the 22 items was used as a measure of current PTSD symptom severity. Cronbach's alpha coefficient for the present sample was 0.93. The SRIP was administered both in 1996 and in 1998.

In 1996 and in 1998, current positive and negative social experiences were measured with the Social Experiences Checklist (SEC; Revenson, Wollmann, \& Felton, 1983; Van Oostrom, Tijhuis, De Haes, Tempelaar, \& Kromhout, 1995). Two scores were summed, one for current positive social interactions and one for current negative social interactions. A four-point Likert scale was used (1=never; 4=often). The reliability of both the positive and negative experiences dimensions was good, with a Cronbach's alpha coefficient of 0.82 for the positive social experiences scale and 0.72 for the negative social experiences scale. The validity of the SEC was confirmed by Pearson correlations with neuroticism, coping styles, and satisfaction with social relationships (Tempelaar, De Haes, Van den Heuvel, \& Van Nieuwenhuijzen, 1987; Van Oostrom et al., 1995). The Cronbach's alpha coefficients for the present study were 0.84 for positive social interactions and 0.79 for negative social interactions.

In 1996, coping was measured with the Dutch adaptation of the Ways of Coping Questionnaire (WCQ; Bramsen, Bleiker, Triemstra, Van Rossum, \& Van der Ploeg, 1995). The Dutch version consists of 41 items reflecting thoughts and behaviours of people dealing with stressful situations. Respondents were asked to recall stressful situations that had occurred to them during the previous 12 months. On a four-point Likert scale (1='not at all'; 4='great deal') respondents could indicate the extent to which each of 41 responses applied to them. The Dutch Ways of Coping Questionnaire consists of six subscales: planful problem solving (8 items), wishful thinking (8 items), seeking social support (6 items), positive reappraisal (6 items), accepting responsibility (6 items), and avoidance (7 items). Reliability and validity of the scales were found to be good (Bramsen et al., 1995). Cronbach alpha coefficients for the subscales for this sample were good to reasonable (between 0.82 and 0.68 ), except for the avoidance scale (alpha $=0.56$ ). Therefore, the avoidance scale was deleted from the analyses. We note that avoidant coping is still present in our analyses because the scale 'Wishful Thinking' also reflects avoidance behaviour and this scale was included in the analyses.

In both 1996 and 1998, a checklist of 15 dichotomous items measured whether the peacekeepers had experienced additional stressful life events. In 1996, respondents were asked whether they had experienced these situations during the previous 12 months, and in 1998, it was asked whether they experienced these situations during the interval between the study in 1996 and that in 1998. These stressful life events addressed the following topics: severe illness or injury of oneself; severe illness or injury of family members or a person close by; death of partner, children, parents, or other important persons; divorce or break up from a long-term relationship; (threat of) unemployment/ discharge; decline in financial position; relationship problems; quarrels within the family; serious problems with a family member; problems with the police; victim of a crime or accident; and abortion/miscarriage. A sum score of all stressful life events endorsed was used.

\subsection{Data analysis}

The bivariate relationships between social support, coping strategies, life events, and PTSD were examined using Pearson correlations. 
Dirkzwager, A.J.E., Bramsen, I., Ploeg, H.M. van der

Social support, coping, life events, and posttraumatic stress symptoms among former peacekeepers: a prospective study.

Personality and Individual Differences: 34, 2003, p. 1545-1559

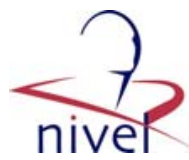

The cross-sectional analyses included hierarchical multiple regression analyses to study the contribution of social support, coping strategies and additional stressful life events to the variance of PTSD symptom severity in 1996. To control for the level of peacekeeping stress, this variable was entered in the first step. In the second step the direct effects of social support, coping strategies, and stressful life events were entered. To examine whether coping strategies and social interactions moderated the relationship between stressful life events and PTSD symptom severity, the interaction effects of stressful life events with each of the coping strategies, as well as supportive and negative social contacts, were entered in step three.

The longitudinal analyses involved hierarchical multiple regression analyses to examine the contribution of social support, coping strategies, and stressful life events to the variance of PTSD symptom severity in 1998. To control for PTSD at time 1, this variable was entered in the first step. In the second step, positive and negative social interactions in 1996 and the coping strategies used in 1996 were entered. The number of stressful life events experienced between 1996 and 1998 was entered in the following step.

\section{RESULTS}

\subsection{Bivariate correlations}

Table 2 presents the intercorrelations between all variables for the Lebanon peacekeepers and for those who participated in peacekeeping operations since 1990. For both groups a similar pattern of correlations was found. As expected, there were a number of significant correlations between the independent variables. However, there was no evidence of multicollinearity between the independent variables (Tabachnik \& Fidell, 1989).

\section{[ TABLE 2 ]}

\subsection{Social support, coping, stressful life events and PTSD at time 1 (1996)}

Table 3 presents data on the cross-sectional hierarchical multiple regression analyses predicting PTSD symptom severity at time 1 . For the group of peacekeepers who went to Lebanon, the following significant direct effects were found. A higher number of potentially traumatic situations during deployment was significantly associated with more PTSD symptom severity. After controlling for the level of stressors during deployment, a higher degree of supportive social interactions was significantly associated with less PTSD symptom severity. More negative social interactions, the coping strategy 'wishful thinking', and a higher number of stressful life events in the preceding 12 months were significantly associated with more PTSD symptoms. No significant interaction effects were found for peacekeepers who went to Lebanon. Altogether the regression model accounted for $41 \%$ of the variance in PTSD symptom severity.

\section{[ TABLE 3 ]}

For the peacekeepers deployed after 1990, a higher degree of PTSD symptom severity in 1996 was associated with a higher number of stressful situations during deployment, more negative social interactions, more use of the coping strategies 'accepting responsibility' and 'wishful thinking', and a higher number of life events in the preceding 12 months. Using planful problem solving as a coping strategy was associated with less PTSD symptom severity. Two significant interaction effects were found: for the coping strategy 'accepting responsibility' and for negative social interactions. To explore the meaning of these interaction effects the subjects were divided (based on percentiles) into three groups: 'weak', 'middle' and 'strong' users of the coping strategy, and those with a 'low', 'middle', and 'high' degree of negative social interactions. For each subgroup the Pearson correlation between the number of stressful life events and PTSD symptom severity was calculated. For accepting responsibility the correlations between the number of stressful life events and PTSD symptom severity for the 'weak', 'middle', and 'strong' users were $0.20,0.31$, and 0.39 , respectively. Thus, there was a stronger relationship between the number of life events and PTSD symptoms in those who used the 
Dirkzwager, A.J.E., Bramsen, I., Ploeg, H.M. van der

Social support, coping, life events, and posttraumatic stress symptoms among former peacekeepers: a prospective study.

Personality and Individual Differences: 34, 2003, p. 1545-1559

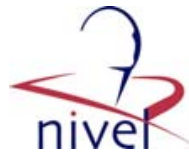

coping strategy 'accepting responsibility' to a higher degree. Pearson correlations between the number of stressful life events and PTSD symptoms for veterans with a 'low', 'middle', and 'high' degree of negative social interactions were $0.15,0.20$, and 0.37 , respectively. Thus, a stronger relationship between the number of life events and PTSD symptoms was found for peacekeepers with a high degree of negative social interactions. The regression model accounted for $47 \%$ of the variance in PTSD symptom severity.

\subsection{Social support, coping, stressful life events and PTSD symptom severity at time $\mathbf{2}$}

Table 4 presents the longitudinal analyses for predicting PTSD symptom severity at time 2 (1998), after controlling for PTSD symptom severity at time 1 (1996). For Lebanon veterans, after controlling for PTSD symptom severity in 1996, both the supportive and negative social interactions in 1996 were significantly associated with PTSD symptom severity in 1998. The coping strategies no longer made a significant contribution to the variance of PTSD symptom severity in 1998. After controlling for the other variables, a higher number of stressful life events between 1996 and 1998 was associated with more PTSD symptoms in 1998. The final regression model explained 63\% of the variance.

\section{[ TABLE 4 ]}

Among the peacekeepers deployed after 1990 supportive social interactions in 1996 and the coping strategies 'wishful thinking' and 'seeking social support' were significantly associated with PTSD symptoms in 1998, after PTSD symptom severity in 1996 was controlled for. More supportive social interactions and using the coping strategy 'seeking social support' were associated with less PTSD symptom severity. Using the coping strategy 'wishful thinking' to a higher degree was associated with more PTSD symptoms. After controlling for the other variables, the number of stressful life events in the interval 1996-1998 was significantly associated with more PTSD symptom severity in 1998. Altogether the final regression model explained 54\% of the variance.

\section{DISCUSSION}

Social support, coping strategies, and additional stressful life events are assumed to play an important role in a person's response to stress (Cohen \& Wills, 1985; King et al., 1998; Lazarus, 1993). However, these issues have not been well studied in peacekeeping personnel at risk of exposure to potentially traumatising and life-threatening situations. The aim of the present study was to examine (cross-sectionally and longitudinally) the relationship between social support, coping strategies, additional stressful life events, and posttraumatic stress symptoms among two groups of Dutch former peacekeepers.

As expected, a higher degree of supportive social interactions in 1996 was significantly associated with fewer PTSD symptoms. This finding concurs with results from previous studies among combat veterans (Flannery, 1990; King et al., 1998; Solomon, Mikulincer, \& Hobfoll, 1987; Sutker et al., 1995). Even after controlling for PTSD symptom severity at time 1 (1996), the degree of supportive social interactions was significantly associated with fewer PTSD symptoms in 1998. The present study examined the influence of both supportive and negative social interactions. A higher degree of negative social interactions was significantly associated with more PTSD symptoms in 1996. In addition, negative social contacts appeared to moderate the relationship between additional stressful life events and PTSD symptoms among the veterans of peacekeeping operations since 1990. A stronger relationship between the number of life events and PTSD symptoms was found for peacekeepers with a high degree of negative social interactions.

Statistically significant associations with PTSD symptoms were found for a number of coping strategies. Consistent with the hypotheses, it appeared that for both groups of veterans using 'wishful thinking' to a higher degree was associated with more PTSD symptoms in 1996. Wishful thinking may reflect an attempt to avoid dealing with the traumatic event. In this way the adjustment process as suggested by Horowitz (1993), in which repetitive intrusions of the traumatic event alternate with avoidance behaviour and feelings of numbness, may not be completed. This could prevent the successful processing of the traumatic event and putting it into the past. Accepting responsibility to a higher degree was associated with more PTSD symptoms in 1996 among those peacekeepers deployed 
Dirkzwager, A.J.E., Bramsen, I., Ploeg, H.M. van der

Social support, coping, life events, and posttraumatic stress symptoms among former

peacekeepers: a prospective study.

Personality and Individual Differences: 34, 2003, p. 1545-1559

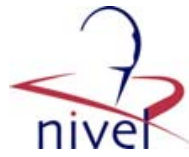

after 1990. This coping strategy may relate to an overvaluation of one's contribution to the traumatic event, and thus to feelings of guilt about what one has or has not done. It may be that persistent trauma-related guilt is not beneficial for processing the events successfully. In addition, accepting responsibility appeared to moderate the impact of additional stressful life events on PTSD symptom severity among those deployed after 1990. The correlation between the number of stressful life events and PTSD symptom severity was stronger for peacekeepers who used accepting responsibility to a high degree. As hypothesised, using planful problem solving strategies to a higher degree was associated with less PTSD symptom severity. After PTSD symptom severity in 1996 was controlled for, wishful thinking and seeking social support were significantly associated with PTSD symptoms in 1998 among those peacekeepers deployed after 1990. These results are in line with previous research, and are consistent with the hypothesis that emotion-focused coping strategies (wishful thinking and accepting responsibility) appear to be associated with more PTSD symptoms, whereas problemfocused coping strategies (planful problem solving and seeking social support) appear to be associated with fewer PTSD symptoms (Fairbank et al., 1991; Folkman \& Lazarus, 1988; Sharkansky et al., 2000; Solomon, Mikulicer, \& Avitzur, 1988).

Coping behaviour not only influences a person's vulnerability to develop posttraumatic stress symptoms, but is also considered to be a consequence of coping resources, such as environmental (e.g. social support) and personal coping resources (e.g. self-efficacy; Holahan, Moos, \& Schaefer, 1996; Lazarus, 1999). Perceived social support may influence the way a person copes with stress and the effectiveness of these coping efforts, and may motivate individuals to seek assistance when it is needed (Pierce, Sarason, \& Sarason, 1996). In the present study, the degree of supportive social interactions was significantly and positively correlated with the following coping strategies: planful problem solving, seeking social support, and positive reappraisal. The degree of negative social interactions was positively correlated with the coping strategies: wishful thinking and accepting responsibility. These findings are in line with previous studies suggesting that people with a supportive social network are more likely to rely on active coping strategies and less likely to use avoidance coping strategies (Holahan \& Moos, 1987).

In agreement with previous longitudinal studies among combat veterans, we found that PTSD symptom severity in 1996 was significantly correlated with both a higher number of stressful life events in the preceding 12 months, and with a higher number of stressful life events in the following 2 years. PTSD symptom severity in 1998 was significantly associated with a higher number of stressful life events in the years 1996-1998 (Sharkansky et al., 2000; Solomon, Mikulincer, \& Flum, 1988). This implies a complex and bilateral relationship between stressful life events and PTSD symptoms. One explanation for this bilateral relationship between PTSD and negative life events may be that particular PTSD symptoms, such as feelings of detachment or estrangement, irritability and outbursts of anger, have a negative influence on social relationships. Therefore, an increased vulnerability for life events in the social realm may be likely, such as problems with friends or family, or a divorce. On the other hand, if PTSD does result in more stressful life events in the social realm and therefore in a depletion of social resources, then having less social support may increase the risk of PTSD symptoms. The fact that the level of negative social interactions moderated the relationship between stressful life events and PTSD seems consistent with this.

Before discussing practical implications of the results, we should acknowledge some methodological limitations of the present study. Firstly, self-report measures were used and the stressful life events were measured retrospectively. This may have caused bias, in that having current PTSD symptoms might influence the way a person reports the number of stressful life events and the perceived social support. For instance, those with many PTSD symptoms may have been inclined to report more stressful life events and less social support in order to account for their current state of psychological distress. In addition, it has been suggested that depression, which often accompanies PTSD, may be associated with an increased report of negative circumstances (Teasdale, 1983). However, in their review, Brewin, Andrews, and Gotlib (1993) concluded that recall of significant past events does not appear to be affected by mood state (Brewin et al., 1993). Secondly, because the present study lacks information on coping strategies, social support and PTSD symptoms in the period prior to 1996 and prior to the deployment, it is difficult to make causal inferences about the relationships. Thirdly, we may express concerns about the representativeness of the study sample. Because the response rate was 
Dirkzwager, A.J.E., Bramsen, I., Ploeg, H.M. van der

Social support, coping, life events, and posttraumatic stress symptoms among former

peacekeepers: a prospective study.

Personality and Individual Differences: 34, 2003, p. 1545-1559

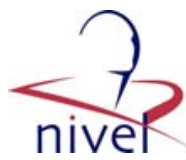

moderate, some selection bias may have occurred. Since the peacekeepers participated anonymously during the first phase of the study, no information about the non-responders at time 1 was available. However, when comparing the peacekeepers who participated in both 1996 and 1998 with those who participated in 1996 only, no significant differences were found for most variables, such as PTSD symptom severity, sleeping problems, somatic complaints, and the mean number of reported potentially traumatic situations during deployment. Therefore, selection bias does not seem to be a major problem in the present study.

These limitations are offset by a number of strengths of the present study. Being able to use a longitudinal design to examine the relationship between social support, coping, life events and PTSD symptoms makes the results of the present study meaningful. Particularly since earlier studies investigating risk factors for PTSD among peacekeeping personnel mainly focused on war-zone related factors and personal factors such as age, gender, and race. Therefore, the present study adds valuable information about the relationships between social support, coping strategies, stressful life events and posttraumatic stress symptoms among peacekeepers. Another strength of the study is the large sample size, allowing us to analyse a group of peacekeepers deployed between 1979 and 1985, and a second group of veterans deployed since 1990.

A number of differences were found between the Lebanon veterans and those deployed since 1990. For instance, in the veterans of operations since 1990 a number of coping strategies (i.e. planful problem solving, accepting responsibility, and seeking social support) were significantly associated with PTSD symptom severity. In addition, in that same group the number of stressors during deployment was significantly associated with PTSD symptoms in 1998 after PTSD symptoms at time 1 were controlled for, whereas this was not the case for the Lebanon veterans. Some explanations for these differences may exist. First, the two groups differ with respect to the time elapsed since deployment. This difference may, for instance, be related to the influence of the number of stressors during deployment. When the time elapsed since deployment is long, other factors (e.g. stressful life events following deployment) may become more important than stressful situations during deployment. However, other differences between the two samples may also be relevant, such as differences in the type and amount of preparation, care during deployment, and the after-care that was available. Thus, more studies are needed to elucidate the impact of differences between peacekeeping operations on both PTSD rates and risk factors for PTSD.

Since the present study indicates that social support and coping strategies appear to be important predictors of PTSD symptoms among peacekeepers, it could be argued that prevention and intervention programs should pay attention to these aspects. Information on the perceived social support and coping strategies of the peacekeeper could be used in the selection procedure and training programs prior to deployment to decrease the risk of psychological adjustment problems following deployment. For example, prevention programs could include social-skills training to enhance supportive social interactions, and training on how to cope with stressors. Based on the results of the present study, peacekeepers could be trained in using active coping strategies, such as planful problem solving and seeking social support in order to try to prevent or decrease PTSD symptoms. Other aspects not examined in the present study may, of course, also help to decrease or prevent PTSD symptoms, such as aspects of cognitive behavioural models (Ehlers \& Clark, 2000). Further research is needed to explore which aspects of prevention and treatment programs are effective in preventing or decreasing PTSD symptoms among military veterans.

Considering the number of ongoing peacekeeping operations and the increase in the number of peacekeeping and peace-enforcement operations since 1990, it is likely that a substantial number of peacekeepers worldwide will be exposed to dangerous or life-threatening situations. The present study shows that coping strategies, the availability of supportive social interactions, and additional stressful life events may influence the vulnerability to develop posttraumatic stress symptoms following exposure to combat stressors. 
Dirkzwager, A.J.E., Bramsen, I., Ploeg, H.M. van der

Social support, coping, life events, and posttraumatic stress symptoms among former peacekeepers: a prospective study.

Personality and Individual Differences: 34, 2003, p. 1545-1559

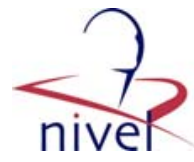

\section{TABLES}

Table 3

Cross-sectional multiple regression analyses predicting PTSD symptom severity in 1996 (time 1)

\begin{tabular}{|c|c|c|c|c|}
\hline & \multicolumn{2}{|c|}{ Lebanon (1979-1985) } & \multicolumn{2}{|c|}{ Operations since 1990} \\
\hline & Beta & $t$ & Beta & $t$ \\
\hline \multicolumn{5}{|l|}{ Direct effects of variables from 1996} \\
\hline Stressors during deployment & 0.21 & $3.98 * * *$ & 0.22 & $5.97 * * *$ \\
\hline Positive social interactions in 1996 & -0.20 & $-3.67 * * *$ & -0.07 & -1.70 \\
\hline Negative social interactions in 1996 & 0.26 & $4.33 * * *$ & 0.28 & $6.34 * * *$ \\
\hline Planful problem solving (1996) & -0.02 & -0.36 & -0.12 & $-2.76^{* *}$ \\
\hline Seeking social support (1996) & 0.02 & 0.30 & -0.07 & -1.65 \\
\hline Wishful thinking (1996) & 0.21 & $3.32 * * *$ & 0.15 & $3.19 * *$ \\
\hline Accepting responsibility (1996) & 0.02 & 0.30 & 0.11 & $2.36^{*}$ \\
\hline Positive reappraisal (1996) & -0.08 & -1.42 & 0.05 & 1.09 \\
\hline Number of life events in preceding 12 months & 0.14 & $2.63 * *$ & 0.15 & $3.80 * * *$ \\
\hline \multicolumn{5}{|l|}{ Interaction of life events with } \\
\hline Planful problem solving & -0.03 & -0.51 & -0.07 & -1.79 \\
\hline Accepting responsibility & 0.00 & 0.05 & 0.10 & $2.20 *$ \\
\hline Wishful thinking & 0.04 & 0.55 & -0.08 & -1.50 \\
\hline Seeking social support & 0.03 & 0.49 & 0.02 & 0.43 \\
\hline Positive reappraisal & 0.02 & 0.35 & -0.07 & -1.67 \\
\hline Positive social interactions & -0.06 & -1.04 & 0.03 & 0.56 \\
\hline Negative social interactions & -0.02 & -0.34 & 0.12 & $2.41 *$ \\
\hline$R$ square & 0.41 & & 0.47 & \\
\hline
\end{tabular}

$$
\begin{aligned}
& \text { * } P<0.05 \\
& \text { ** } P<0.01 \\
& \text { *** } P<0.001
\end{aligned}
$$

Table 1

Mean scores on the research variables for both groups of peacekeepers

\begin{tabular}{llrrrr}
\hline & $\begin{array}{l}\text { Lebanon } \\
(1979-1985)\end{array}$ & & $\begin{array}{l}\text { Peacekeeping } \\
\text { operations } \\
\text { since 1990 }\end{array}$ & \multirow{2}{*}{$t(\mathrm{df})$} \\
\cline { 2 - 5 } & $\mathrm{M}$ & $\mathrm{r}$ & $\mathrm{M}$ & $\mathrm{SD}$ & \\
\hline PTSD symptom severity (1996) & 29.95 & 10.03 & 27.89 & 8.23 & $3.16(794)^{* *}$ \\
PTSD symptom severity (1998) & 30.63 & 9.35 & 27.90 & 7.48 & $4.57(803)^{* * *}$ \\
Stressors during deployment & 7.06 & 3.17 & 5.11 & 3.63 & $7.79(808)^{* * *}$ \\
Positive social interactions (1996) & 21.27 & 4.26 & 22.24 & 4.04 & $-3.25(806)^{* *}$ \\
Negative social interactions (1996) & 11.87 & 3.46 & 11.00 & 2.84 & $3.88(806)^{* * *}$ \\
Planful problem solving (1996) & 19.76 & 4.87 & 19.58 & 5.06 & $0.48(740)$ \\
Seeking social support (1996) & 13.80 & 3.41 & 14.32 & 3.60 & $-1.97(745)^{*}$ \\
Wishful thinking (1996) & 14.02 & 4.67 & 13.79 & 4.31 & $0.68(743)$ \\
Accepting responsibility (1996) & 11.26 & 3.20 & 11.28 & 3.34 & $-0.06(742)$ \\
Positive reappraisal (1996) & 11.36 & 3.46 & 12.30 & 3.60 & $-3.49(742)^{* *}$ \\
Life events in year prior to 1996 & 2.16 & 1.67 & 1.80 & 1.44 & $3.31(808)^{* *}$ \\
Life events in interval 1996-1998 & 2.04 & 1.51 & 1.84 & 1.49 & $1.79(808)$ \\
\hline
\end{tabular}

$$
\begin{aligned}
& * P<0.05 \\
& \text { ** } P<0.01 \\
& \text { *** } P<0.001
\end{aligned}
$$


Dirkzwager, A.J.E., Bramsen, I., Ploeg, H.M. van der

Social support, coping, life events, and posttraumatic stress symptoms among former

peacekeepers: a prospective study.

Personality and Individual Differences: 34, 2003, p. 1545-1559

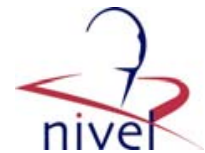

Table 2

Pearson correlations between all variables for the peacekeepers of Lebanon and for those deployed after 1990

\begin{tabular}{|c|c|c|c|c|c|c|c|c|c|c|c|c|}
\hline & 1 & 2 & 3 & 4 & 5 & 6 & 7 & 8 & 9 & 10 & 11 & 12 \\
\hline 1. PTSD symptom severity in 1996 & - & $0.73 * * *$ & $0.33 * * *$ & $*-0.32 * * *$ & $0.50^{* * *}$ & $* 0.00$ & 0.02 & $0.43 * * *$ & $0.26^{* * * *}$ & -0.10 & $0.31 * * *$ & $0.29 * * *$ \\
\hline 2. PTSD symptom severity in 1998 & $0.69 * * *$ & - & $0.29 * * *$ & $*-0.34 * * *$ & $0.53 * * *$ & $* 0.08$ & 0.05 & $0.46^{* * *}$ & $0.35 * * *$ & -0.05 & $0.33 * * *$ & $0.41 * * *$ \\
\hline 3. Stressors during deployment & $0.36^{* * *}$ & $0.30 * * *$ & - & 0.02 & $0.27 * * *$ & $* 0.07$ & 0.07 & $0.18^{* *}$ & $0.13^{*}$ & 0.02 & $0.23^{* * *}$ & $0.15^{* *}$ \\
\hline 4. Positive social interactions- 1996 & $-0.23 * * *$ & $*-0.26 * * *$ & -0.04 & - & $-0.25 * * *$ & $* 0.16^{* *}$ & $0.23 * * *$ & $*-0.15 *$ & -0.10 & $0.23 * * *$ & -0.04 & -0.05 \\
\hline 5. Negative social interactions- 1996 & $0.54 * * *$ & $* 0.44 * * *$ & $0.22 * *$ & $-0.24 * * *$ & - & 0.08 & 0.03 & $0.45 * * *$ & $0.33 * * *$ & 0.00 & $0.27 * * *$ & $0.31 * * *$ \\
\hline 6. Planful Problem Solving-1996 & -0.08 & 0.06 & 0.07 & $0.31 * * *$ & 0.03 & - & $0.30 * * *$ & $0.16^{* *}$ & $0.47 * * *$ & $0.47 * * *$ & 0.04 & -0.02 \\
\hline 7. Seeking Social Support - 1996 & -0.07 & $-0.12 * *$ & 0.03 & $0.36 * * *$ & -0.02 & $0.32 * *$ & & $0.16^{* *}$ & $0.15^{*}$ & $0.33 * * *$ & $0.14 *$ & 0.07 \\
\hline 8. Wishful Thinking - 1996 & $0.42 * * *$ & $* 0.38 * * *$ & $0.17 * *$ & -0.09 & $0.41 * *$ & $* 0.05$ & $0.20^{* * *}$ & - & $0.53 * * *$ & 0.07 & $0.21 * * *$ & $0.31 * * *$ \\
\hline 9. Accepting Responsibility - 1996 & $0.32 * * *$ & $* 0.25 * * *$ & $0.19 * *$ & 0.04 & $0.33 * * *$ & $* 0.41 * * *$ & $* 0.21 * * *$ & $0.51 * * *$ & - & $0.38 * * *$ & $0.13 *$ & $0.19 * *$ \\
\hline 10. Positive Reappraisal - 1996 & 0.00 & -0.03 & 0.09 & $0.32 * * *$ & 0.01 & 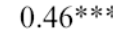 & * $0.28 * * *$ & 0.03 & $0.27 * * *$ & - & 0.01 & -0.02 \\
\hline 11. Life events in year prior to 1996 & $0.34 * * *$ & $* 0.28 * * *$ & $0.12 *$ & -0.04 & $0.30^{* * *}$ & $* 0.01$ & 0.07 & $0.29 * * *$ & $0.18 * * *$ & 0.07 & - & $0.48 * * *$ \\
\hline 12. Life events in interval 1996-1998 & $0.28 * * *$ & $0.36 * * *$ & 0.06 & -0.03 & $0.25 * * *$ & $* 0.05$ & 0.07 & $0.25 * * *$ & $0.22 * * *$ & 0.03 & $0.43^{* * * *}$ & - \\
\hline
\end{tabular}

Above the diagonal the Pearson correlations are shown for the peacekeepers who went to Lebanon $(N=310-281)$. Below the diagonal the Pearson correlations for the peacekeepers who participated in peacekeeping operations after 1990 are shown $(N=498-452)$. Because 48 peacekeepers did not complete the Ways of Coping Questionnaire the data of these persons were excluded from analyses involving the WCQ, resulting in a maximum response of 291 peacekeepers who went to Lebanon and 471 deployed after 1990

** $P<0.01$

*** $P<0.001$ 
Dirkzwager, A.J.E., Bramsen, I., Ploeg, H.M. van der

Social support, coping, life events, and posttraumatic stress symptoms among former peacekeepers: a prospective study.

Personality and Individual Differences: 34, 2003, p. 1545-1559

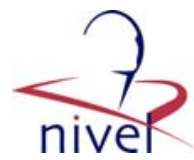

Table 4

Longitudinal multiple regression analyses predicting PTSD symptom severity in 1998 (time 2), while controlling for PTSD symptom severity in 1996

\begin{tabular}{|c|c|c|c|c|}
\hline \multirow[t]{2}{*}{ Effect } & \multicolumn{2}{|c|}{ Lebanon (1979-1985) } & \multicolumn{2}{|c|}{ Operations since 1990} \\
\hline & Beta & $t$ & Beta & $t$ \\
\hline Number of stressors during deployment & 0.05 & 1.33 & 0.10 & $2.78 * *$ \\
\hline PTSD symptom severity in 1996 & 0.52 & $10.66 * * *$ & 0.52 & $12.06 * * *$ \\
\hline \multicolumn{5}{|l|}{ Social support } \\
\hline Positive social interactions in 1996 & -0.14 & $-3.31 * *$ & -0.08 & $-2.04 *$ \\
\hline Negative social interactions in 1996 & 0.10 & $2.17 *$ & 0.04 & 0.85 \\
\hline \multicolumn{5}{|l|}{ Coping strategies } \\
\hline Planful problem solving (1996) & 0.07 & 1.42 & 0.02 & 0.45 \\
\hline Seeking social support (1996) & 0.04 & 1.01 & -0.10 & $-2.64 * *$ \\
\hline Wishful thinking (1996) & 0.05 & 0.98 & 0.11 & $2.61 * *$ \\
\hline Accepting responsibility (1996) & 0.08 & 1.53 & -0.03 & -0.60 \\
\hline Positive reappraisal (1996) & -0.05 & -1.17 & 0.01 & 0.13 \\
\hline Stressful life events between 1996 and 1998 & 0.18 & $4.36^{* * * *}$ & 0.18 & $5.22 * * *$ \\
\hline$R$ Square & 0.63 & & 0.54 & \\
\hline
\end{tabular}

$* P<0.05$

** $P<0.01$

*** $P<0.001$

\section{REFERENCES}

1. American Psychiatric Association. (1994). Diagnostic and statistical manual of mental disorders (4th ed.). Washington, DC: American Psychiatric Association.

2. Archibald, H. C., \& Tuddenham, R. D. (1965). Persistent stress. Reaction after combat. A 20year follow-up. Archives of General Psychiatry, 12, 475-481.

3. Benotsch, E. G., Brailey, K., Vasterling, J. J., Uddo, M., Constans, J. I., \& Sutker, P. B. (2000). War zone stress, personal and environmental resources, and PTSD symptoms in Gulf war veterans: a longitudinal prospective. Journal of Abnormal Psychology, 109(2), 205-213.

4. Bramsen, I., Bleiker, E. M. A., Triemstra, A. H. M., Van Rossum, S. M. G., \& Van der Ploeg, H. M. (1995). A Dutch adaptation of the ways of coping questionnaire: factor structure and psychometric properties. Anxiety, Stress and Coping, 8, 337-352.

5. Bramsen, I., \& Van der Ploeg, H. M. (1999). Fifty years later: the long-term psychological adjustment of aging World War II survivors. Acta Psychiatrica Scandinavica, 100, 350-358.

6. Brewin, C. R., Andrews, B., \& Gotlib, I. H. (1993). Psychopathology and early experience: a reappraisal of retrospective reports. Psychological Bulletin, 113(1), 82-98.

7. Cohen, S., \& Wills, T. A. (1985). Stress, social support, and the buffering hypothesis. Psychological Bulletin, 98, 310- 357.

8. Ehlers, A., \& Clark, D. M. (2000). A cognitive model of posttraumatic stress disorder. Behaviour Research and Therapy, 38(4), 319-345.

9. Fairbank, J. A., Hansen, D. J., \& Fitterling, J. M. (1991). Patterns of appraisal and coping across different stressor conditions among former prisoners of war with and without posttraumatic stress disorder. Journal of Consulting and Clinical Psychology, 59(2), 274-281.

10. Flannery, R. B. (1990). Social support and psychological trauma: a methodological review. Journal of Traumatic Stress, 3(4), 593-611.

11. Folkman, S., \& Lazarus, R. S. (1988). Coping as a mediator of emotion. Journal of Personality and Social Psychology, 54(3), 466-475.

12. Folkman, S., Lazarus, R. S., Gruen, R. J., \& Delongis, A. (1986). Appraisal, coping, health status, and psychological symptoms. Journal of Personality and Social Psychology, 50(3), 571-579.

13. Fontana, A., \& Rosenheck, R. (1994). Posttraumatic Stress Disorder among Vietnam Theater Veterans. A causal model of etiology in a community sample. Journal of Nervous and Mental Disease, 182(12), 677-684. 
Dirkzwager, A.J.E., Bramsen, I., Ploeg, H.M. van der

Social support, coping, life events, and posttraumatic stress symptoms among former peacekeepers: a prospective study.

Personality and Individual Differences: 34, 2003, p. 1545-1559

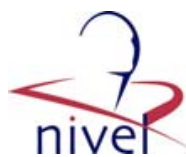

14. Friedman, M. J., Schnurr, P. P., \& McDonagh-Coyle, A. (1994). Post-traumatic stress disorder in the military veteran. Psychiatric Clinics of North America, 17(2), 265-277.

15. Green, B. L., Grace, M. C., Lindy, J. D., Gleser, G. C., \& Leonard, A. (1990). Risk factors for PTSD and other diagnoses in a general sample of Vietnam veterans. American Journal of Psychiatry, 147(6), 729-733.

16. Holahan, C. J., \& Moos, R. H. (1987). Personal and contextual determinants of coping strategies. Journal of Personality and Social Psychology, 52(5), 946-955.

17. Holahan, C. J., Moos, R. H., \& Schaefer, J. A. (1996). Coping, stress resistance, and growth: conceptualizing adaptive functioning. In M. Zeidner, \& N. S. Endler (Eds.), Handbook of coping: theory, research, applications (pp. 24-39). New York: John Wiley \& Sons.

18. Horowitz, M. J. (1993). Stress-response syndromes. In J. P. Wilson, \& B. Raphael (Eds.), International handbook of traumatic stress syndromes (pp. 49-60). New York: Plenum Press.

19. Hovens, J. E., Bramsen, I., \& Van der Ploeg, H. M. (2000). Zelfinventarisatielijst Posttraumatische Stressstoornis (ZIL): Handleiding. [Self-Rating Inventory for PTSD: Manual.]. Lisse, the Netherlands: Swets \& Zeitlinger.

20. Hovens, J. E., Van der Ploeg, H.M., Bramsen, I ., Klaarenbeek, M. T. A., Schreuder, J. N., \& Rivero, V. V. (1994). The development of the Self-Rating Inventory for Posttraumatic Stress Disorder. Acta Psychiatrica Scandinavica, 90, 172-183.

21. King, L. A., King, D. W., Fairbank, J. A., Keane, T. M., \& Adams, G. A. (1998). ResilienceRecovery factors in Post- Traumatic Stress Disorder among female and male Vietnam veterans: hardiness, postwar social support, and additional stressful life events. Journal of Personality and Social Psychology, 74(2), 420-434.

22. King, D. W., King, L. A., Foy, D. W., Keane, T. M., \& Fairbank, J. A. (1999). Posttraumatic stress disorder in a national sample of female and male Vietnam veterans: risk factors, warzone stressors, and resilience-recovery variables. Journal of Abnormal Psychology, 108(1), 164-170.

23. Kulka, R. A., Schlenger, W. E., Fairbank, J. A., Hough, R. L., Jordan, B. K., Marmar, C. R., \& Weiss, D. S. (1990). Trauma and the Vietnam war generation. Report of findings from the National Vietnam Veterans Readjustment Study. New York: Brunner/Mazel, Publishers.

24. Lazarus, R. S. (1993). Coping theory and research: past, present, and future. Psychosomatic Medicine, 55, 234-247.

25. Lazarus, R. S. (1999). Stress and emotions: a new synthesis. New York: Springer Publishing Company.

26. Litz, B. T. (1996). The psychological demands of peacekeeping for military personnel. Clinical Quarterly, 6(1), 1-8.

27. Litz, B. T., King, L. A., King, D. W., Orsillo, S. M., \& Friedman, M. J. (1997). Warriors as peacekeepers: features of the Somalia experience and PTSD. Journal of Consulting and Clinical Psychology, 65(6), 1001-1010.

28. Litz, B. T., Orsillo, S. M., Friedman, M., Ehlich, P., \& Batres, A. (1997). Posttraumatic stress disorder associated with peacekeeping duty in Somalia for U.S. military personnel. American Journal of Psychiatry, 154(2), 178-184.

29. MacDonald, C., Chamberlain, K., Long, N., \& Mirfin, K. (1996). Psychological effects of peacekeeping deployments on military personnel. Palmerston North: Massey University, Department of Psychology.

30. Mehlum, L., \& Weisaeth, L. (2002). Predictors of posttraumatic stress reactions in Norwegian U.N. peacekeepers 7 years after service. Journal of Traumatic Stress, 15(1), 17-26.

31. Pierce, G. R., Sarason, I. G., \& Sarason, B. R. (1996). Coping and social support. In M. Zeidner, \& N. S. Endler (Eds.), Handbook of coping: theory, research, applications (pp. 434451). New York: John Wiley \& Sons.

32. Revenson, T. A., Wollmann, C. A., \& Felton, B. J. (1983). Social support as stress buffers for adult cancer patients. Psychosomatic Medicine, 45, 321-331.

33. Sarason, I. G., Sarason, B. R. (Eds.). (1985). Social support: theory, research, and applications. The Hague: Martinus Nijhoff.

34. Sharkansky, E. J., King, D. W., King, L. A., \& Wolfe, J. (2000). Coping with Gulf War combat stress: mediating and moderating effects. Journal of Abnormal Psychology, 109(2), 188-197.

35. Solomon, Z., Mikulincer, M., \& Avitzur, E. (1988). Coping, locus of control, social support, and combat-related posttraumatic stress disorder: a prospective study. Journal of Personality and Social Psychology, 55(2), 279-285. 
Dirkzwager, A.J.E., Bramsen, I., Ploeg, H.M. van der

Social support, coping, life events, and posttraumatic stress symptoms among former peacekeepers: a prospective study.

Personality and Individual Differences: 34, 2003, p. 1545-1559

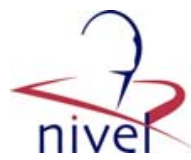

36. Solomon, Z., Mikulincer, M., \& Flum, H. (1988). Negative life events, coping responses and combat related psychopathology: a prospective study. Journal of Abnormal Psychology, 97(3), 302-307.

37. Solomon, Z., Mikulincer, M., \& Hobfoll, S. E. (1987). Objective versus subjective measurement of stress and social support: combat-related reactions. Journal of Consulting \& Clinical Psychology, 55(4), 577-583.

38. Sutker, P. B., Davis, J. M., Uddo, M., \& Ditta, S. R. (1995). War zone stress, personal resources, and PTSD in Persian Gulf War returnees. Journal of Abnormal Psychology, 104(3), 444-452.

39. Tabachnik, B. G., \& Fidell, L. S. (1989). Using multivariate statistics, 2nd edition. New York: HarperCollins Publishers.

40. Teasdale, J. D. (1983). Negative thinking in depression: cause, effect or reciprocal relationship?. Advances in Behavior Research and Therapy, 5, 3-25.

41. Tempelaar, R., De Haes, J. C. J. M., Van den Heuvel, W. J. A., \& Van Nieuwenhuijzen, M. G. (1987). Een meetinstrument voor positieve en negatieve sociale ervaringen van (kanker-) patienten [A measurement instrument for positive and negative social experiences of (cancer-) patients]. Tijdschrift voor Sociale Gezondheidszorg, 65(20), 648- 653.

42. Van Oostrom, M. A., Tijhuis, M. A. R., De Haes, J. C. J. M., Tempelaar, R., \& Kromhout, D. (1995). A measurement of social support in epidemiological research: the social experiences checklist tested in a general population in the Netherlands. Journal of Epidemiology and Community Health, 49, 518-524.

43. Weisaeth, L., Aarhaug, P., Mehlum, L., \& Larsen, S. (1993). The UNIFIL study, positive and negative consequences of service in UNIFIL contingents I-XXVI, Report part I, Results and recommendations. Oslo: Norwegian Defence Command Headquarters. The joint medical service.

44. Zeidner, M., \& Ben-Zur, H. (1994). Individual differences in anxiety, coping, and post-traumatic stress in the aftermath of the Persian Gulf War. Personality and Individual Differences, 16(3), 459-476. 